psychiatrists is to learn to convey information in such a way that letters enhance the therapeutic relationship and do not risk alienating the family.

\section{Declaration of interest}

None.

\section{References}

DEPARTMENT OF HEALTH (2003) Copying Letters to Patients: Good Practice Guidelines. London: Department of Health.
MARZANSKI, M., MUSUNURI, P. \& COUPE, T. (2005) Copying letters to patients: a study of patients' views. Psychiatric Bulletin, 29, 56-58.

ROY, D. (2004) Recording health care and sharing the information - more bureaucracy or a welcome change to prevailing practice? Psychiatric Bulletin 28, 33-35.

SAIN, K., TAN, W. M. \& MARKAR, H. (2005) Should GP letters be copied to psychiatric outpatients? Progress in Neurology and Psychiatry, 9, 24-27.

SUBOTSKY, F. (2005) Copying letters to patients: issues for child and adolescent mental health services. Psychiatric Bulletin, 29, 201-203.

TAHIR, T. A., BISSON, J. I. \& WILCOX, J.

(2005) Copying clinic letters to psychiatric patients. Psychiatric Bulletin, 29, 327-329.

Gillian Combe Specialist Registrar, Child and Adolescent Mental Health Service, Delancey Hospital, Cheltenham, Clare Short Specialist Registrar, Riverside Adolescent Unit, Blackberry Hill Hospital, Bristol, *Helen Stephens Specialist Registrar, East Bristol Child and Adolescent Mental Health Service, Buckingham Gardens, Downend, Bristol, email: helenstephens@doctors.org.uk

\title{
Auditing the care programme approach for people with learning disability: a 4-year audit cycle
}

\section{AIMS AND METHOD}

Annual audits of the enhanced care programme approach (CPA) were conducted from 2002 to 2005 to evaluate and improve the implementation of CPA in two inner-London community learning disability services. The CPA standards included those stipulated by the Department of Health. The notes of all patients on enhanced CPA were analysed using a structured data collection form.

\section{RESULTS}

There was a gradual improvement in the attainment of targets by both services. Areas of strength included allocating a date for the next CPA review, crisis plans and documentation of service users' comments.
Areas of weakness included completion and review of risk assessments and the availability of a care plan for the previous 6 months.

\section{CLINICAL IMPLICATIONS}

Completing the audit cycle and reauditing improves attainment of targets and encourages service development, but further progress is required.
The care programme approach (CPA) is considered a model of good practice in delivering efficient, effective and coordinated mental healthcare in the community. It was introduced in April 1991 to ensure that individuals received appropriate after-care following discharge from hospital. It identified four key components: systematic arrangements for the assessment of health and social needs, the formulation of a care plan, the allocation of a named keyworker who would monitor the individual and coordinate care, and the requirement of a regular review of the individual's needs and revision of the care plan (Department of Health, 1990).

The CPA has evolved over the years following further guidance and recommendations by the Department of Health, which has acknowledged problems such as professionals finding the CPA process bureaucratic and service users finding the process inconsistent. Important changes in the implementation of the CPA were highlighted in two key publications: Effective Care Coordination in Mental Health Services: Modernising the Care Programme Approach (Department of Health, 1999a) and The National Service Framework for Mental Health
(Department of Health, 1999b). The CPA now encompasses all individuals receiving input from specialist mental health services, in all settings, including residential and community care, and is not just simply an after-care arrangement. Two levels of CPA have been developed 'standard' and 'enhanced' - addressing the different needs of individuals.

The Department of Health has given great importance to audit and the assessment of the quality of CPA implementation. An audit pack has been issued for this purpose as a guidance (Department of Health, 2001a).

\section{The need for CPA in learning disability}

The importance of CPA in learning disability is highlighted by the increased prevalence of mental health problems among people with such disability compared with the general population. Several epidemiological studies have shown that rates vary between 10 and 39\% (BorthwickDuffy, 1994).

People with learning disabilities often have complex physical, psychological and social needs and therefore 


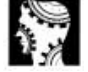

original papers
Box 1. Standards set in 2004 and 2005.

New standards set in 2004

- Issues addressed in meeting

- Housing

- Benefits

- Employment

- Physical health

New standards set in 2005

- Review of risk assessment in past 12 months

- Health action plans

- Joint CPA and community care assessment?

CPA, care programme approach

1. Service A only.

proper care planning is important, especially for those with additional mental health problems. Notwithstanding this, the implementation of CPA in services for people with learning disabilities has been patchy and inconsistent
(Roy, 2000). Valuing People (Department of Health 2001b) clarified that people with learning disability who have mental health problems should have full access to the CPA process.

An audit of CPA and risk assessment and management across 19 learning disability services in the South Thames region revealed that only 6 services were completing formal implementation of CPA, with no formal implementation in 7 services (Brooks et al, 2005). Selby \& Alexander (2004) published a 3-year audit of an in-patient forensic service assessing patient involvement and satisfaction with the CPA process and the views of professionals. The approach of appointing a 'non-professional' care coordinator proved to be advantageous. A satisfaction rating of $96 \%$ was awarded by the service users. Bhaumik et al (2005) analysed inpatient CPA records over a 6 -month period, with emphasis placed on the completion of a risk management plan. Only 4 out of the 15 patients whose cases were reviewed had a risk management plan available on

Table 1. Cases meeting standards and reaching targets for each service, 2002-5

\begin{tabular}{|c|c|c|c|c|c|c|c|c|}
\hline \multirow{3}{*}{ Year } & \multicolumn{8}{|c|}{ Cases meeting standards, \% } \\
\hline & \multicolumn{2}{|c|}{2002} & \multicolumn{2}{|c|}{2003} & \multicolumn{2}{|c|}{2004} & \multicolumn{2}{|c|}{2005} \\
\hline & $A(n=35)$ & $\mathrm{B}(n=21)$ & $A(n=36)$ & B $(n=18)$ & $A(n=28)$ & $\mathrm{B}(n=19)$ & $A(n=28)$ & $B(n=22)$ \\
\hline CPA form - 6 months $^{1}$ & 46 & 71 & 39 & 61 & $82^{2}$ & 26 & 79 & 77 \\
\hline CPA form - 12 months ${ }^{1}$ & 88 & 67 & 64 & 72 & 92 & 74 & 50 & $100^{2}$ \\
\hline Form present & 97 & 100 & 100 & 100 & 50 & 60 & 100 & 100 \\
\hline No care plan at all & 3 & 0 & 0 & 0 & 4 & 11 & 0 & 0 \\
\hline Care coordinator appointed ${ }^{1}$ & 97 & 86 & 100 & 89 & 96 & 90 & 96 & $100^{2}$ \\
\hline \multicolumn{9}{|l|}{ Profession of care coordinator } \\
\hline Care manager & 60 & 29 & 50 & 50 & 25 & 45 & 45 & 45 \\
\hline Nurse & 29 & 48 & 39 & 33 & 55 & 40 & 39 & 45 \\
\hline Psychiatrist & 0 & 10 & 0 & 0 & 0 & 0 & 0 & 5 \\
\hline Psychologist & 3 & 0 & 0 & 0 & 5 & 0 & 0 & 0 \\
\hline Other & 3 & 0 & 6 & 11 & 16 & 15 & 12 & 5 \\
\hline Not recorded & 3 & 14 & 6 & 6 & 0 & 0 & 4 & 0 \\
\hline GP details ${ }^{1}$ & 91 & 76 & 95 & 89 & $96^{2}$ & 74 & $96^{2}$ & 59 \\
\hline Risk assessment ${ }^{1}$ & 54 & 48 & 81 & 78 & 82 & 63 & 89 & 82 \\
\hline Review of risk assessment ${ }^{1}$ & - & - & - & - & - & - & 54 & 45 \\
\hline Next CPA date allocated ${ }^{1}$ & 86 & 48 & 83 & 86 & $96^{2}$ & 73 & $96^{2}$ & $95^{2}$ \\
\hline Crisis plan ${ }^{1}$ & 91 & 81 & 94 & 83 & 93 & 90 & 89 & $95^{2}$ \\
\hline Service user comments ${ }^{1}$ & 51 & 38 & 47 & 28 & $93^{2}$ & 52 & $82^{2}$ & $82^{2}$ \\
\hline Carer comments $^{1}$ & 20 & 19 & 14 & 17 & $62^{2}$ & $48^{2}$ & 43 & $68^{2}$ \\
\hline RMO signature ${ }^{1}$ & 74 & 81 & 78 & 40 & 75 & 53 & 57 & $91^{2}$ \\
\hline Care manager signature & 31 & 29 & 28 & 65 & 18 & 16 & 19 & 40 \\
\hline Service user signature ${ }^{1}$ & 23 & 67 & 18 & 40 & 45 & 37 & 19 & $58^{2}$ \\
\hline Care coordinator signature ${ }^{1}$ & 49 & 71 & 70 & 68 & 68 & 68 & 57 & $95^{2}$ \\
\hline \multicolumn{9}{|l|}{ Issues addressed in meeting } \\
\hline Housing & & & & & 65 & 30 & 93 & 100 \\
\hline Benefits & & & & & 40 & 40 & 50 & 95 \\
\hline Employment & & & & & 50 & 18 & 79 & 100 \\
\hline Physical health & & & & & 75 & 85 & 71 & 95 \\
\hline Health action plans & & & & & & & 4 & 23 \\
\hline Joint CPA/CCA & & & & & & & 39 & \\
\hline Not recorded & & & & & & & 36 & \\
\hline
\end{tabular}

CCA, community care assessment; CPA, care programme approach; GP, general practitioner; RMO, responsible medical officer.

1. Targets for standards set in $2004 / 5$

2. Targets achieved. 
discharge. The audit also highlighted deficiencies in information-sharing.

\section{Aims and objectives of the audit}

The aim of the audit reported here was to evaluate and improve the quality of implementation of enhanced CPA in two inner-London learning disability services. Individuals assigned to enhanced CPA are more likely to have multiple needs and require input from several professions, have severe mental illness requiring frequent and intensive intervention and are more likely to have comorbid problems such as substance misuse, neurological and developmental problems and personality disorders. They have a greater probability of posing a risk to themselves or others and often have a forensic history or disengage with services (Department of Health, 1999a). Our objectives were to assess performance against standards, including those recommended by the Department of Health (2001a).

\section{Method}

The study investigated two inner-London disability services, referred to here as service $A$ and service $B$. Both services use a multidisciplinary approach in the management of people with learning disability and have been implementing the CPA since 1998. A retrospective audit of all service users on enhanced CPA was conducted yearly from 2002 to 2005. The key areas of the CPA process to be examined (standards) were agreed by both sites. The standards were reviewed and updated on an annual basis according to the results of each audit, in order to address areas where performance was poor. After the initial phase of assessing performance, targets were set for certain standards that were considered to be of particular significance in 2004 and 2005 (Box 1). The government audit pack was not used owing to the small scale of the audits.

Both services had a local database of service users assigned to the CPA and this was used to generate a list for each service. Care coordinators updated the lists on the databases and they might not have been comprehensive or up to date. However, steps were taken to encourage all care coordinators to update the list prior to commencement of the audit. The notes were then obtained and an audit questionnaire, incorporating the standards, was applied to the care plan in the notes. The data generated were analysed by the local mental health and social care trust clinical governance team, the results were presented annually to the multidisciplinary teams and the implications for practice discussed.

\section{Results}

The results of each audit are reported in Table 1. The total number of patients on enhanced CPA in service A was 32 (35\% of the total on CPA, the remainder being on standard level); the corresponding number in service $B$ was

\section{Box 2. Suggestions for improvement}

- 2002

Establishment of CPA database (serviceA) In-house CPA training for all new staff members at least once a year (both services) Establishment of CPA working party group (service B)

\section{- 2003}

30-day reminders for reviews (service $A$ ) Inclusion of prompts on CPA form (service B) Staff supervision also includes CPA monitoring (service B) Setting targets for standards (both services) Explicit linking of service user comments to person-centred planning service objectives (service A)

\section{- 2004}

CPA included in supervision sessions for care managers (service B)

Care coordinator assumes responsibility for obtaining signatures (service B)

\section{- 2005}

Unified CPA form to be used by both services with specific subheadings and further prompts Inclusion of patient demographics/diagnosis Accessible care plans

CPA, care programme approach.

$20(33 \%$ of the total). Most care coordinators were care managers or nurses at both sites.

The combined targets achieved by both services in 2004 included the presence of a care plan, recording of general practitioner details, allocating a CPA follow-up date (or stating a named person to arrange a follow-up date) and documentation of service users' and carers' comments. Overall, 5 out of 11 targets were achieved. In 2005 the combined targets achieved included recording a named care coordinator, arranging a follow-up date, presence of a crisis plan, recording of general practitioner details, service users' and carers' comments, and presence of consultant psychiatrist and care coordinator signatures. Overall, 10 out of 13 targets were achieved. Other topics increasingly addressed at meetings were housing and employment. Health action plans were offered only to a minority of service users in either service despite being significant policy milestones (Department of Health, 2001b).

Weak areas were completion or updating of the risk assessment, and the availability of a care plan for every 6 months.

\section{Discussion}

The CPA has been implemented in the two learning disability services in this study for several years and to our knowledge no other service of a similar nature has completed such comprehensive and consecutive audit cycles. Both learning disability services have modified the local CPA policy to reflect the issues most relevant to adults with learning disabilities who have mental illness or significant behavioural problems. The CPA has been 


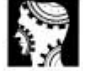

original papers embraced by most professions within both services, although psychologists have been reluctant to act as care coordinators and to apply CPA because of the approach's mental illness perspective on psychological problems and also because of the episodic nature of their work with service users. The audit cycle has revealed a continuing trend of improvement in most standards since 2002, with a greater number of targets being achieved in 2005. However, some standards have shown a rise and fall over time. Potential contributors to this were changes in filing systems, meaning forms were not always available, and key staff being on long-term leave, delaying review meetings or reducing their quality.

The result of each audit is presented to all members of both health and social care teams to ensure that everyone is aware of the progress made and where further progress is needed. Staff are always asked for suggestions for improvement, and ideas that we have implemented as part of the audit cycle are listed in Box 2 . These changes may go some way to explain the general improvement in performance. In addition we have set up a multiprofessional CPA monitoring group to ensure that the database is up to date and that any problems in improving practice are resolved. Feedback from the team presentations has shown that CPA has improved liaison between different professionals and has ensured that certain issues such as risk are discussed and recorded and that information is shared more easily. The main disadvantage is that the CPA meetings are not easily accessible to service users. Anecdotal evidence suggests that service users and their carers see the CPA meetings as an opportunity to meet all professionals and that the meetings act as regular review points which can effect positive change in the case management plans.

The audit did not assess whether care plans are actually being disseminated to service users and their carers, and it would be useful to question the former regarding their understanding and satisfaction with the CPA process. We are currently addressing this through the respective service communication plans, including the development of accessible CPA care plans. Future audits will assess performance in these areas, and will include information on patient demographics and diagnoses. There will be more emphasis on person-centred planning and health action plans, and consideration is being given to auditing standard CPA.

\section{Declaration of interest}

None.

\section{References}

BHAUMIK, S., NADKARNI, S. S. BISWAS, A. B., et al (2005) Service innovations: risk assessment in learning disability. Psychiatric Bulletin, 29, 28-31.

BORTHWICK-DUFFY, S. A. (1994)

Epidemiology and prevalence of psychopathology in people with mental retardation. Journal of Consulting and Psychology, 62, 17-27.

BROOKS, D., SPILLER, M. J. \& BOURAS N. (2005) Report on the SouthThames Regional Audit of CPA and Risk Assessment/Management Implementation in Services for People with Learning Disabilities and Menta Health Problems. http://

www.estiacentre.org/docs/ CPA\%20Audit.pdf

DEPARTMENT OF HEALTH (1990) The Care ProgrammeApproach for People with a Mental Illness Referred to the Specialist Psychiatric Services ( $\mathrm{HC}(90) 23)$. London: Department of Health.

DEPARTMENT OF HEALTH (1999a) Effective Care Coordination in Mental
Health Services. Modernising the Care Programme Approach. London: Department of Health.

DEPARTMENT OF HEALTH (1999b) A National Service Framework for Mental Health. Modern Standards and Service Models for Mental Health. London: Department of Health. DEPARTMENT OF HEALTH (2001a) An Audit Pack for Monitoring the Care Programme Approach. London: Department of Health.

DEPARTMENT OF HEALTH (2001b)

Valuing People: A New Strategy for People with Learning Disabilities for the 21st Century. London: Department of Health.

ROY, A. (2000) The Care Programme Approach in learning disability psychiatry. Advances in Psychiatric Treatment, 6, 380-387.

SELBY, G. \& ALEXANDER, R. T. (2004) Care Programme Approach in a forensic Journal of Forensic Practice, 6, 26-32. learning disability service. British

Afia Ali Senior House Officer, Camden Learning Disability Service, London, Ian Hall Consultant Psychiatrist and Honorary Senior lecturer in Psychiatry of Learning Disability, Department of Mental Health Sciences, Royal Free and University College London Medical School, London, ClaireTaylor Team Leader, Islington Learning Disability Partnership, London, Stephen Attard Senior House Officer, Islington Learning Disability Partnership, London, ${ }^{*}$ Angela Hassiotis Senior Lecturer and Honorary Consultant Psychiatrist in Learning Disability Department of Mental Health Sciences, Royal Free and University College London Medical School, 48 Riding House Street, London WIW7EY,email: a.hassiotis@ucl.ac.uk 